\title{
Experimental Study on Freeze-Thaw Effects on Creep Characteristics of Rubber Concrete
}

\author{
Qi Li $\left(\mathbb{D},{ }^{1}\right.$ Fei Xu $\mathbb{D}^{2,3,4}$ Hemin Zheng, ${ }^{5}$ Junhao Shi, ${ }^{1}$ and Jianyu Zhang ${ }^{3}$ \\ ${ }^{1}$ School of Civil Engineering, Shijiazhuang Tiedao University, Shijiazhuang 050043, Hebei, China \\ ${ }^{2}$ State Key Laboratory of Geomechanics and Geotechnical Engineering,Institute of Rock and Soil Mechanics, \\ Chinese Academy of Sciences, Wuhan, Hubei 430071, China \\ ${ }^{3}$ Key Laboratory of Large Structure Health Monitoring and Control, Shijiazhuang Tiedao University, Shijiazhuang 050043, \\ Hebei, China \\ ${ }^{4}$ School of Civil Engineering, Southwest Jiaotong University, Chengdu 610031, Sichuan, China \\ ${ }^{5}$ China Railway Design Group Co.,Ltd., 300308 Tianjin, China
}

Correspondence should be addressed to Fei Xu; xufei@stdu.edu.cn

Received 17 August 2021; Revised 11 December 2021; Accepted 14 December 2021; Published 4 January 2022

Academic Editor: Shengwen Tang

Copyright (c) 2022 Qi Li et al. This is an open access article distributed under the Creative Commons Attribution License, which permits unrestricted use, distribution, and reproduction in any medium, provided the original work is properly cited.

\begin{abstract}
Crumb Rubber Concrete (CRC) can exhibit high freeze-thaw resistance, but its long-term creep behavior under various freezethaw conditions remains unclear, which is essential for the safety of pavement engineering in the severe cold zone. In this study, the freeze-thaw effects on the creep behavior of CRC under different stress levels were systematically analyzed by testing the compressive strength, the uniaxial creep under different stress levels, and the dynamic elastic modulus. To simulate real conditions of the road environment in the cold area, the lowest temperature of $-20^{\circ} \mathrm{C}$, six freeze-thaw cycles of $0,30,60,90,120$, and 150 , and seven different stress levels of $0.4,0.5,0.6,0.7,0.8$, and 0.9 of the compressive strength were employed in this study. The test results showed that the mass loss rate was $6 \%-11.2 \%$ and the compressive strength decreased by $6.51 \%-47 \%$ after $30-150$ freeze-thaw cycles. When the stress level reached its critical value, the relative dynamic elastic modulus decreased with the number of freezethaw cycles. After 150 freeze-thaw cycles, failure did not appear when the stress level was lower than 50\%, above which the creep failure was determined by the stress level and the number of the freeze-thaw cycles. Meanwhile, it was found that the cracking and interfacial debonding between the matrix and the crumb rubber particle were the main reasons for the degradation of CRC creep performance. Finally, a Weibull distribution-based empirical creep damage model was established to predict the failure of CRC, which can enhance its application to related engineering.
\end{abstract}

\section{Introduction}

The number of waste tires has been increasing with a speed of 1000 million per year, and there will be 5000 million tires in total by the year 2030 [1], which imposes a challenge to the disposal of waste tires. Traditional disposal methods such as landfilling, burning, and fuel may cause air, water, and soil pollution [2-5]. The addition of rubber particles produced from waste tires into concrete may be an efficient way [6-9] to develop a type of rubberized concrete called Crumb Rubber Concrete (CRC), in which the highly elastic and stable rubber particles with a size of $0.425-4.75 \mathrm{~mm}$ were incorporated. However, replacing the sand or stone with rubber particles may weaken the compressive strength, elastic modulus, and tensile strength due to the low modulus of rubber and the weak interface between the matrix and the rubber particle [10-14]. Zhang et al. [15] used FA and GGBS as cement-based materials and used rubber particles to replace $10 \%$ of the fine aggregate to study the mechanical properties and freeze-thaw properties of CRC concrete. The results show that $\mathrm{CRC}$ concrete has good frost resistance due to the energy absorption and dissipation of CRC. Nevertheless, these disadvantages can be overcome by surface treatments upon rubber particles and optimization of mix proportion. Besides, CRC can exhibit better performance upon the impact resistance, ductility, energy dissipated 
energy capacity, high-temperature resistance, and thermal and sound insulation, particularly the frost resistance [16-19]. Wang et al. [20] summarized the principles and classifications of seven fractal dimensions commonly used in cement-based materials and discussed the application of these fractal functions in the study of macroscopic properties of cement-based materials (including durability, permeability, and frost resistance).

In the cold zone, the cyclic frost and freeze-thaw cycles can seriously damage the concrete, cause spalling, and coarsen the pore structure, a process of making the material change from dense to lose. When concrete is seriously damaged, the structural durability and mechanical properties safety and reliability of engineering structures can be reduced and cause sudden hazards [14, 21-23]. Wang et al. [24] discussed the influence of different fineness and content of PHS instead of fly ash mixed into cement on hydration, mechanical strength, concrete pore structure, and fractal dimension. The results showed that PHS with high fineness is more prone to pozzolanic reaction, consumes more $\mathrm{Ca}$ $(\mathrm{OH}) 2$, and makes the concrete structure denser. Wang et al. [25] studied the effects of different reactivity and different dosages of $\mathrm{MgO}$ on the shrinkage and crack resistance of panel concrete through the slab test system. The test results show that the reactive $\mathrm{MgO}$ with a relatively high dosage is suggested to eliminate the early shrinkage and improve the cracking resistance of face slab concrete. Huang et al. [26] used multiscale modeling to simulate the hydration and pore structure of MOS cement and used MATLAB to visualize the pore structure state of the cement system before and after hydration based on the microstructure method. The axial compressive properties of rubber concrete at low temperatures $\left(-30^{\circ} \mathrm{C}\right)$ were investigated by Xue and Pei [27]. They found that the strength and deformation ability of rubber concrete could be obviously improved compared with that of ordinary concrete. Meanwhile, Hora and Reiterman [28] noted that limited degradation in elastic modulus and flexural strength after 200 freeze-thaw cycles could be observed when the rubber-based powder was employed. When the rubber particle was treated in $\mathrm{NaOH}$ solution, after 246 freeze-thaw cycles, the reduction in the mass loss and dynamic modulus could be pronouncedly relieved [29-31]. Also, properly adjusting the size of rubber particles can obtain a significant improvement in the frost resistance of concrete [32-34]. The main reason for the improvement in the frost or freeze-thaw resistance is that the thermal conductivity of rubber is much lower than that of concrete. Moreover, rubber particles are soft, which is beneficial to accommodate incompatible deformation [30, 35, 36].

Bompa and Elghazouli [37] investigated the creep response of unconfined and FRP-confined rubberized concrete materials with relatively high rubber contents; it was found that both confined and unconfined rubberized concrete materials tended to develop higher creep coefficients than that of ordinary concrete. The creep tests of CRC with different strength levels were carried out by Youssf et al. [38], and they found that CRC could exhibit higher creep strains compared to conventional concrete. Adamu [39] reported that around an $81 \%$ increase in the creep strain and about double the creep coefficient could be obtained when 10 vol \% sand was replaced by crumb rubber. Srubar [40] established a random service life model through the natural chloride ion migration test. Due to the randomness of the creep damage of rubber concrete, conventional concrete damage models are unable to reflect its true state, but the Weibull probability distribution function has a prominent advantage of describing the random damage and is widely used in the field of reliability evaluation [41]. Chen and Qiao [42] and Pham et al. [43] applied the Weibull probability distribution function to study concrete under different conditions. Gao et al. [44] and Lu et al. [45] conducted orthogonal experiments on self-compacting concrete roads with nanomolecules and fitted concrete fatigue equations with different survival rates based on the two-parameter Weibull probability fatigue equation. Therefore, an appropriate probability damage model is of great significance to comprehensively and effectively evaluate the creep damage of rubber concrete under the action of cyclic freeze-thaw. However, for road and bridge engineering, investigations upon the material creep characteristics of CRC under the effect of freeze-thaw cycles are not sufficient.

This paper aims to study the effects of freeze-thaw cycles on the creep behavior of CRC subjected to different stress levels. Rubber particles with a diameter of $3 \sim 6 \mathrm{~mm}$ were incorporated into C40 ordinary concrete by replacing $10 \%$ of the fine aggregates in the volume. After $30,60,90,120$, and 150 freeze-thaw cycles, the compressive strength, uniaxial creep, and dynamic elastic modulus were comprehensively measured. Furthermore, the microstructural change was observed by scanning electric microscope (SEM) test. Moreover, to take the randomness of the material damage into account, a Weibull distribution-based empirical creep damage model was established to predict the creep failure of CRC, which provides an experimental and theoretical basis for applying CRC in road engineering in cold areas.

\section{The Sample Preparation and Test Scheme}

2.1. Raw Materials. In this study, rubber particles are produced by crushing waste rubber tires. At the microscale, they exhibit a porous, layered, and loose structure, as shown in Figure 1.

The ordinary Portland cement (P.O 42.5) was used as the basic cement-based blinder; for ingredients, see Table 1 . The river sand with a fineness modulus of 2.8 was used as the fine aggregate, and crushed stones with $5-20 \mathrm{~mm}$ continuous gradation were selected as the coarse aggregate, following the requirement of Chinese Standard GB/T50081-2019. The Grade I fly ash was obtained from a thermal power plant in China. In addition, the standard high-performance polycarboxylic acid water reducer (HPWR) was adopted to get good workability.

2.2. Mix Proportion. The test specimens were made by mixing the cement, sand, stone, water, fly ash, and water reducing agent following the benchmark ratio of $310: 791$ : 


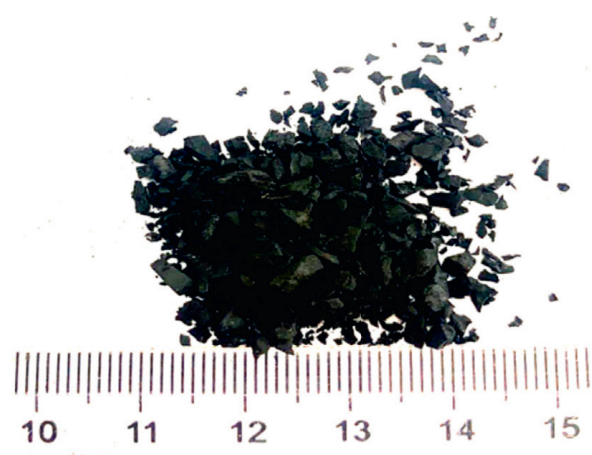

(a)

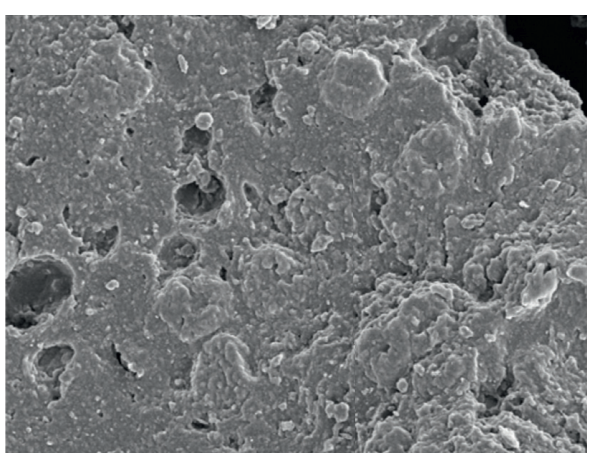

(b)

FIGURE 1: Snapshots of rubber particles: (a) macrorubber particles and (b) microstructure by electron microscope photo.

TABLe 1: Detailed parameters of P.O 42.5.

\begin{tabular}{|c|c|c|c|c|c|c|c|}
\hline $\begin{array}{l}\text { Water consumption of standard } \\
\text { consistency }(\%)\end{array}$ & $\begin{array}{l}\text { Initial setting time } \\
\qquad(\mathrm{min})\end{array}$ & $\begin{array}{l}\text { Final setting time } \\
(\text { min })\end{array}$ & $\begin{array}{l}\text { Burning rate } \\
(\%)\end{array}$ & $\begin{array}{c}\mathrm{MgO} \\
(\%)\end{array}$ & $\begin{array}{l}\mathrm{SO}_{3} \\
(\%) \\
\end{array}$ & $\mathrm{Cl}^{-}(\%)$ & Stability \\
\hline 25.9 & 165 & 220 & 3.5 & 2.18 & 1.93 & 0.009 & Qualified \\
\hline
\end{tabular}

$1115: 150: 50: 3.4$, as tabulated out in Table 2 . The designed concrete strength grade is $\mathrm{C} 40$. The rubber particles with a particle size of $3 \sim 6 \mathrm{~mm}$ were used to replace $10 \%$ medium sand in the concrete. The concrete production process is shown in Figure 2; firstly, the rubber, gravel, sand, fly ash, and cement were mixed and stirred for 60 seconds; the mixture should be removed from the mold and put into the curing box (SHBY-90B) at a temperature of $20^{\circ} \mathrm{C}$ and a humidity of $95 \%$ for 28 days.

\subsection{Test Scheme}

2.3.1. Compressive Strength. Cubic plastic molds with an edge length of $70.7 \mathrm{~mm}$ were used to cast specimens. The casting process of specimens is in accordance with Chinese Standard GB/T50081-2019 [46]. Afterwards, all specimens were transferred to the curing box with a constant temperature of $20 \pm 1{ }^{\circ} \mathrm{C}$ and relative humidity of no less than $95 \%$. After 28-day curing, the specimens were subjected to 0 , $30,60,90,120$, and 150 freeze-thaw cycles, respectively, and three specimens were prepared for each cyclic freeze-thaw test. In the test, the displacement loading with a rate of $3 \mathrm{~mm} / \mathrm{min}$ was adopted to monotonously load until the specimen failed. The strength was evaluated by multiplying the strength of the nonstandard specimen by the size conversion factor of 0.9 , as shown in

$$
f_{c u}=0.9 \times \frac{F}{A} .
$$

2.3.2. Determination of Spalling Quantity. The spalling quantity refers to the ratio of the spalling quantity of surface mortar to the surface area of the specimen after the freezethaw test, as shown in
TABle 2: Mix proportions of CRC $\left(\mathrm{kg} \cdot \mathrm{m}^{-3}\right)$.

\begin{tabular}{lcccccc}
\hline Cement & Water & Sand & Stone & Fly ash & WRA & Rubber \\
\hline 310 & 150 & 593 & 115 & 50 & 3.4 & 36 \\
\hline
\end{tabular}

$$
Q_{S}=\frac{M}{A}
$$

where $Q_{s}\left(\mathrm{~kg} / \mathrm{m}^{2}\right)$ is the amount of spalling per unit area; $A$ $\left(\mathrm{m}^{2}\right)$ is the area of each face of the CRC specimen; $M\left(\mathrm{~kg} / \mathrm{m}^{2}\right)$ is the cumulative spalling amount after the freeze-thaw test.

2.3.3. Uniaxial Creep Test. In this test, the cylindrical specimen with $25 \mathrm{~mm}$ in radius and $100 \mathrm{~mm}$ in height was adopted. Moreover, the standard curing condition as aforementioned was employed. After curing, these specimens were put into the DWR-4 concrete freeze-thaw test machine, as shown in Figure 3. The temperature control range of the test machine is from -40 to $50^{\circ} \mathrm{C}$, and the cooling rate is greater than $20^{\circ} \mathrm{C} / \mathrm{h}$. During freezing and thawing, the minimum and maximum temperature in the center of the specimen should be controlled at $-18 \pm 2^{\circ} \mathrm{C}$ and $5 \pm 2^{\circ} \mathrm{C}$. Each freeze-thaw cycle shall be completed within $4 \sim 6 \mathrm{~h}$, and the thawing time should not be less than one-quarter of the duration of each freeze-thaw cycle. After different freeze-thaw cycles, the CLY15016 electronic creep relaxation tester was used to conduct uniaxial compressive and graded creep tests on the CRC specimens. A loading rate of $0.5 \mathrm{kN} / \mathrm{s}$ was applied to obtain the uniaxial compressive strength, denoted as $f_{c}$.

In the compression creep test, a graded equal increment test method with the loading rate of $0.5 \mathrm{MPa} / \mathrm{s}$ was used, and the first-level stress was designed as $40 \%$ of the uniaxial compressive strength, recorded as $\sigma=0.4 f_{c}$; then each level of the stress was gradually increased by $10 \%$ the compressive 


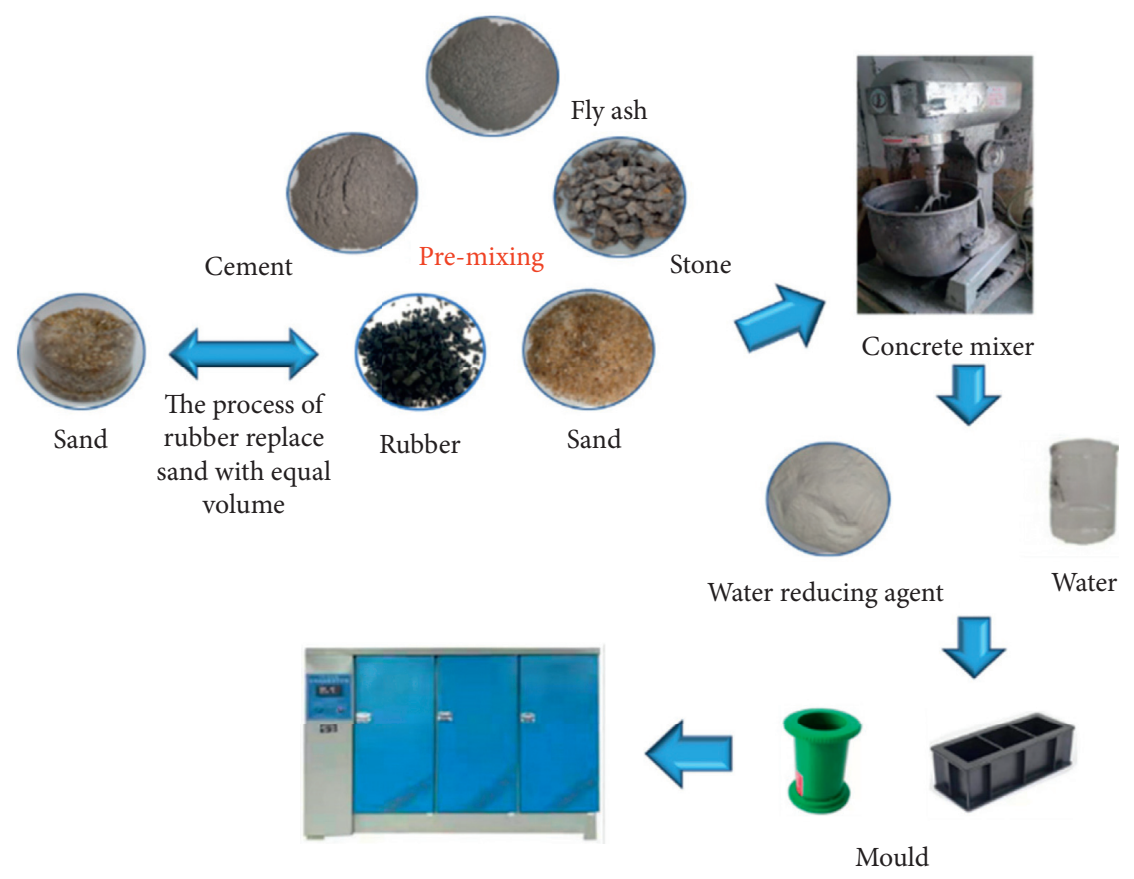

Figure 2: The production process for rubber concrete.

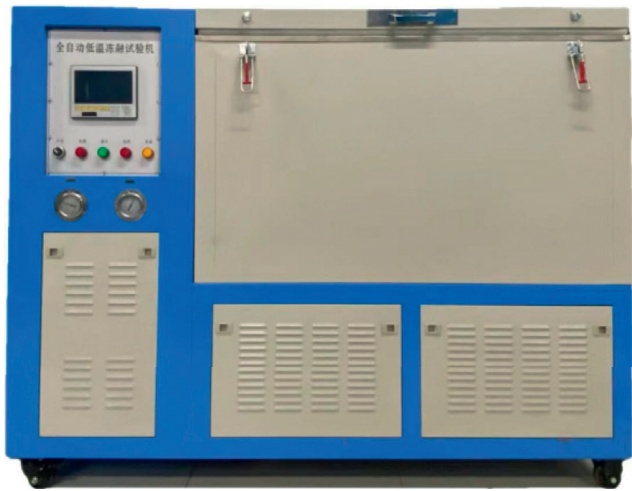

Figure 3: Concrete rapid freezing and thawing test machine.

strength and maintained for $12 \mathrm{~h}$. Besides, the loading system can automatically adjust the stress according to the data feedback so as to ensure that the applied load keeps constant during the creep process. The loading device can be illustrated in Figure 4.

\section{Test Results and Analysis}

3.1. Appearance and Spalling of CRC Caused by Freeze-Thaw Cycles. The durability of CRC can be directly reflected by the development of the cracks and the spalling degree. Therefore, the surface spalling was analyzed to present the macrodamage by carrying out CRC freeze-thaw tests and observing surface characteristics. The appearance of CRC specimens after 6 different numbers of freeze-thaw cycles is shown in Figure 5.

From this figure, it can be seen that after $0-30$ freezethaw cycles, the surface of the CRC specimens was relatively flat, and the edges and corners can be clearly distinguished.

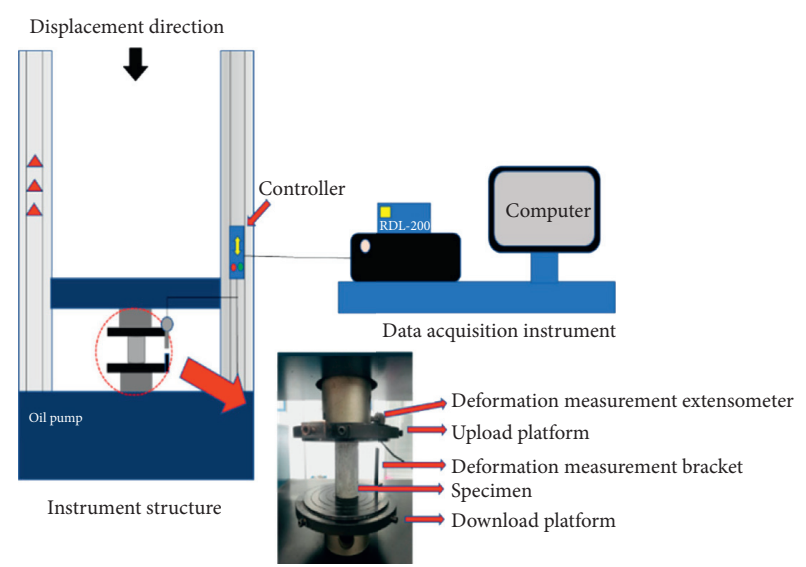

Figure 4: Uniaxial creep load test device.

After 60 freeze-thaw cycles, the CRC surface began to spall off, and the surface became rough, while the edges and corners became unclear and the surface was uneven after 150 freeze-thaw cycles.

3.2. Analysis of Compressive Strength. Figure 6 shows the variation of compressive strength with the number of freezethaw cycles. It can be found that the CRC compressive strength decreased with the number of freeze-thaw cycles and exhibited an obvious downward trend. Compared with the CRC without experiencing freeze-thaw cycles, after 30-150 cycles of freeze-thaw, the uniaxial compressive strength decreased from $6.51 \%$ to $47 \%$. Compared to the specimen after 0 freeze-thaw cycles, the spalling amount of CRC surface gradually increased with the freeze-thaw cycle, the spalling quantity was increased by $6 \%-11.2 \%$, especially 

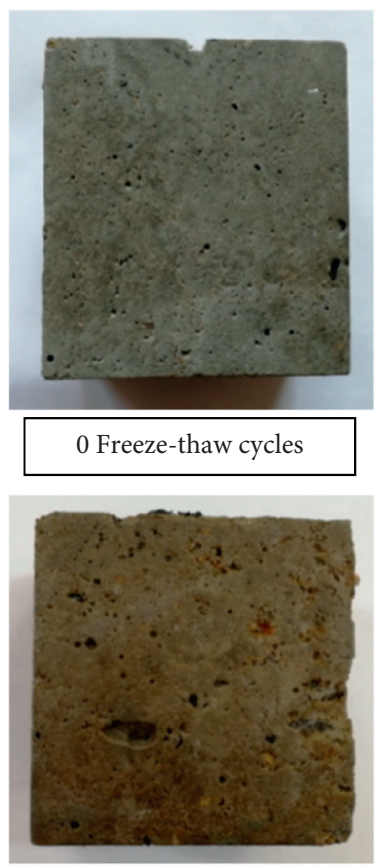

90 Freeze-thaw cycles

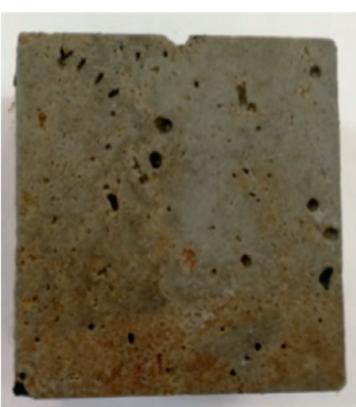

30 Freeze-thaw cycles

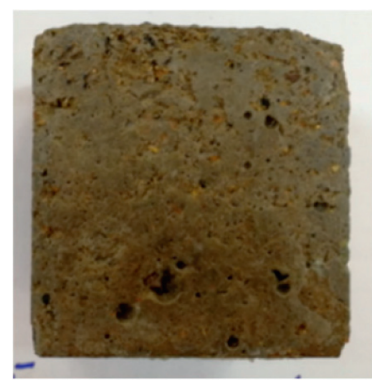

120 Freeze-thaw cycles

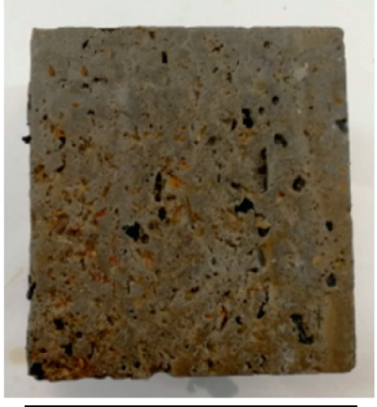

60 Freeze-thaw cycles

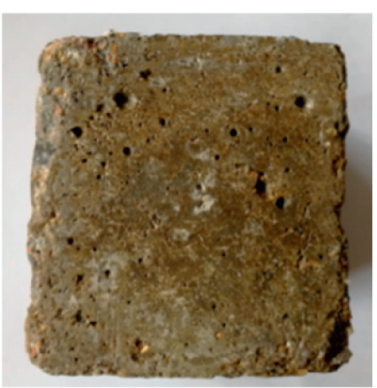

150 Freeze-thaw cycles

FIGURE 5: Appearance of CRC after different freeze-thaw cycles.

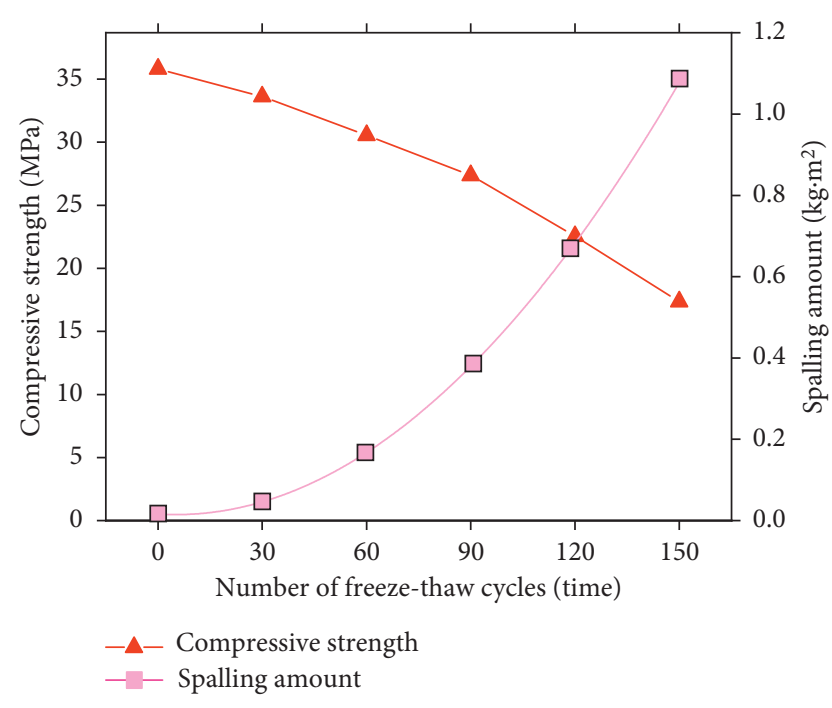

FIGURE 6: Variation curve of CRC spalling amount.

after 60 freeze-thaw cycles, and the surface erosion phenomenon became significant. The greatly changed appearance and morphology of the CRC specimens and the spalling amount that reached the maximum indicate the serious damage of CRC.

Because of the hydrophobicity of the rubber particle, the wall effect can appear at the fresh state of CRC, as a result of which the interfacial performance between the rubber particle and the concrete matrix is usually weak. When the large temperature difference appears, the interface can be easily damaged, and cracking may occur, particularly under serious freeze-thaw conditions as discussed in this study. The initiation of new cracks can help absorb more water in the defects, which can further weaken the CRC specimen on the basis of the osmotic pressure theory. Ultimately, the compressive strength decreases until losing its bearing capacity.

3.3. Creep Behavior Analysis. The relationship between the stress level and the instantaneous strain of CRC after freezethaw cycles is shown in Figure 7(a). It can be seen that the CRC creep curve rose stepwise with the applied stress. The elastic instantaneous deformation occurred first. Thereafter, the stress level was kept constant, and the creep deformation increased almost linearly with time. Under low-level stress, the initial elastic strain was dominant, and the strain gradually increased with axial stress, which mainly displayed a low-speed creep or constant speed creep. At the failure stage, creep mainly showed three stages: low-speed creep, constant speed creep, and speed increasing creep.

After the CRC freeze-thaw test, the relationship between the stress level and the instantaneous strain is shown in Figure 7(b). With the increase of the number of freeze-thaw cycles, the instantaneous deformation of CRC under the action of different horizontal stress increased linearly. Under the impact of the first-level stress $\left(\sigma=0.4 f_{c}\right)$, compared with the initial instantaneous strain of CRC without experiencing freeze-thaw cycles, the initial instantaneous strains of CRC after 30,60,90,120, and 150 freeze-thaw cycles increased by $7.98 \%, 25.24 \%, 56.23 \%$, and $89.96 \%$, respectively. It took 70 hours to fail for the CRC specimen without being subjected to cyclic freeze-thaw, while it was 40 hours for the CRC specimens after experiencing 150 freeze-thaw cycles under the stress level of $0.7 f_{c}$. This indicates that, with the increase of freeze-thaw cycles, the more serious and the 


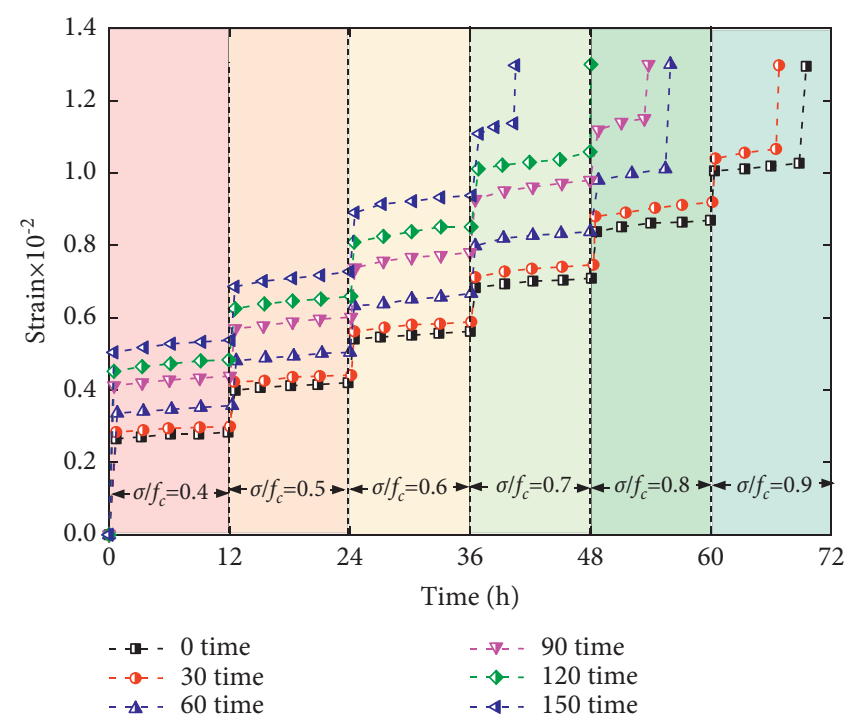

(a)

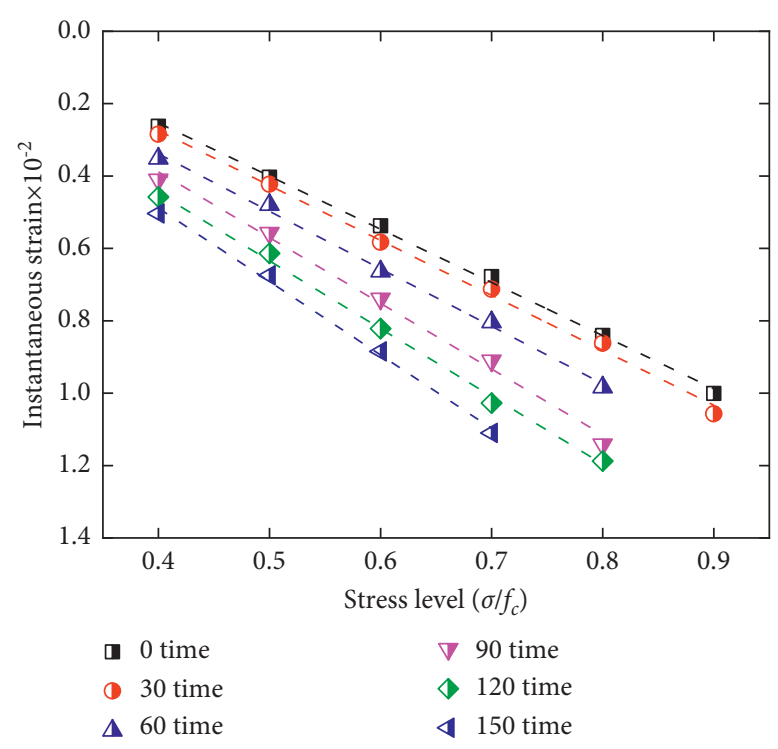

(b)

FIGURE 7: Relationship between stress level (a) and instantaneous strain (b) of CRC after cyclic freeze-thaw. (a) CRC-graded compression creep curve after freeze-thaw cycles. (b) Relationship between stress level and instantaneous strain of RC after a freeze-thaw cycle.

earlier damage of CRC can occur. Meanwhile, the instantaneous deformation increases, but the creep damage degree decreases. The relationship can be fitted by equation (3), and parameters in equation (3) are listed out in Table 3.

$$
F(x, y)=a x+b \text {. }
$$

3.4. The Critical Stress of CRC Creep Failure and Dynamic Elastic Modulus. Previous studies mainly focus on the effect of freeze-thaw cycles on the change of peak stress, but the characteristics of the deformation are ignored. Here, to explore the influence of freeze-thaw cycles on the CRC creep parameters, the ratio of CRC creep strain $\varepsilon c$ to the total strain $\varepsilon t$ after different numbers of freeze-thaw cycles was defined as $\beta$ in equation (4). The increase of $\beta$ indicates the occurrence of CRC creep behavior.

$$
\beta=\frac{\varepsilon_{c}}{\varepsilon_{t}} \times 100 \% .
$$

Figure 8(a) shows the variation of $\beta$ with the stress level. We can find that, at low-level stress, $\beta$ decreased with the stress level. When the stress level reached a critical value, $\beta$ gradually increased with the stress level. This is mainly because the elastic instantaneous strain $\varepsilon_{0}$ dominates the total strain $\varepsilon_{t}$ before the stress level reaches its critical value. Beyond this critical value, the internal damage of CRC was aggravated, which led to the significant increase of $\varepsilon_{c}$, and $\beta$ showed an exponentially increasing trend. By contrast, regarding the CRC experiencing 0 cycles of freeze-thaw, when the stress level $\sigma / f_{c}$ increased from 0.4 to 0.7 , the $\beta$ value decreased from $6.48 \%$ to $5.14 \%$. Seriously, when the stress degree $\sigma / f_{c}$ increased to $0.8, \beta$ increased to $12.59 \%$ in the end. On the other hand, the critical stress for the creep failure decreased with the increase in the number of freeze-thaw
TABle 3: Fitting parameters under different freeze-thaw cycles.

\begin{tabular}{lccccc}
\hline \multirow{2}{*}{ Fitting parameters } & \multicolumn{5}{c}{ Number of the freeze-thaw cycles } \\
& 30 & 60 & 90 & 120 & 150 \\
\hline$a$ & -0.1985 & 0.1902 & -0.1471 & -0.1709 & -0.1313 \\
$b$ & 1.2585 & 1.2987 & 1.3575 & 1.5583 & 1.6070 \\
$R^{2}$ & 0.9993 & 0.9983 & 0.9983 & 0.9969 & 0.9989 \\
\hline
\end{tabular}

cycles. Furthermore, Figure 8(b) shows that the increase of the stress level can decrease the relative dynamic elastic modulus of CRC. When the stress level was $\sigma / f_{c}=0.5$, the decreasing rate became more sharply. For example, when the stress level increased to 0.6 , the relative dynamic elastic modulus of the CRC specimens decreased by $4.17 \%, 7.53 \%$, $9.89 \%, 11.11 \%, 14.94 \%$, and $31.58 \%$ after experiencing 0 to 150 cycles of freeze-thaw, respectively. Referring to the literature and test data, it can be concluded that when the creep stress of the CRC specimen is less than $50 \%$ of the compressive strength, creep failure cannot occur, and the specimen is safe. When this critical value is exceeded, the safety should be evaluated according to the stress level, the loading time, and the number of freeze-thaw cycles.

\section{Microstructural Analysis}

The microstructural change determines the macrodamage evolution of materials [47-50]. In this section, SEM was applied to observe the development of internal creep damage of CRC under freezing and thawing conditions, and the results are displayed in Figures 9-14.

Figure 9 displays the micrographs of CRC specimens before and after exposure to the freeze-thaw cycles. As for CRC specimens, the CRC rubber particles are well bonded to the concrete matrix (see Figure 7), and the constituents of 


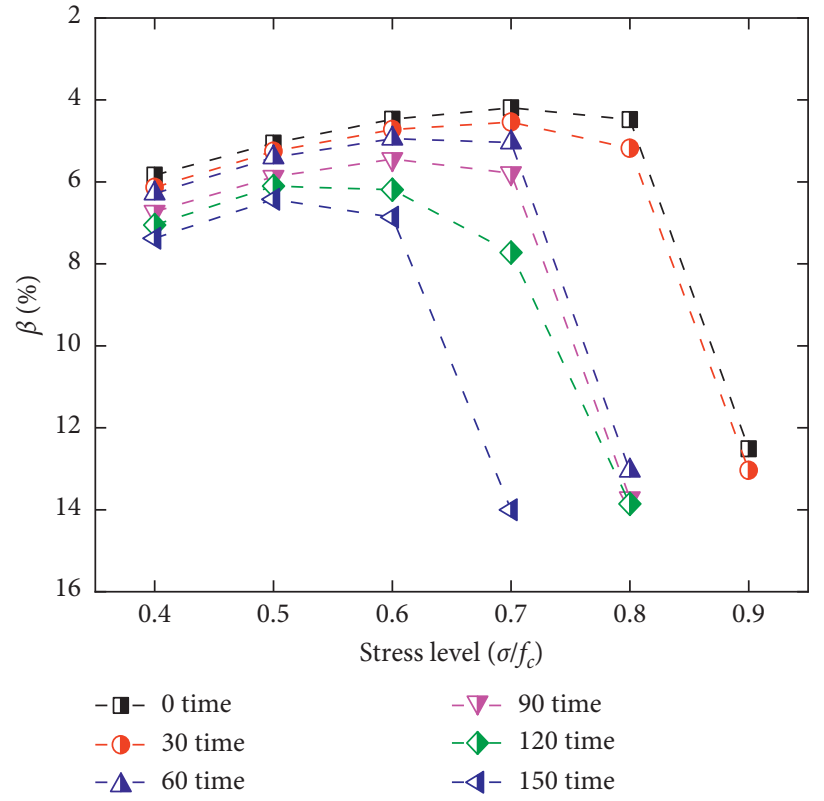

(a)

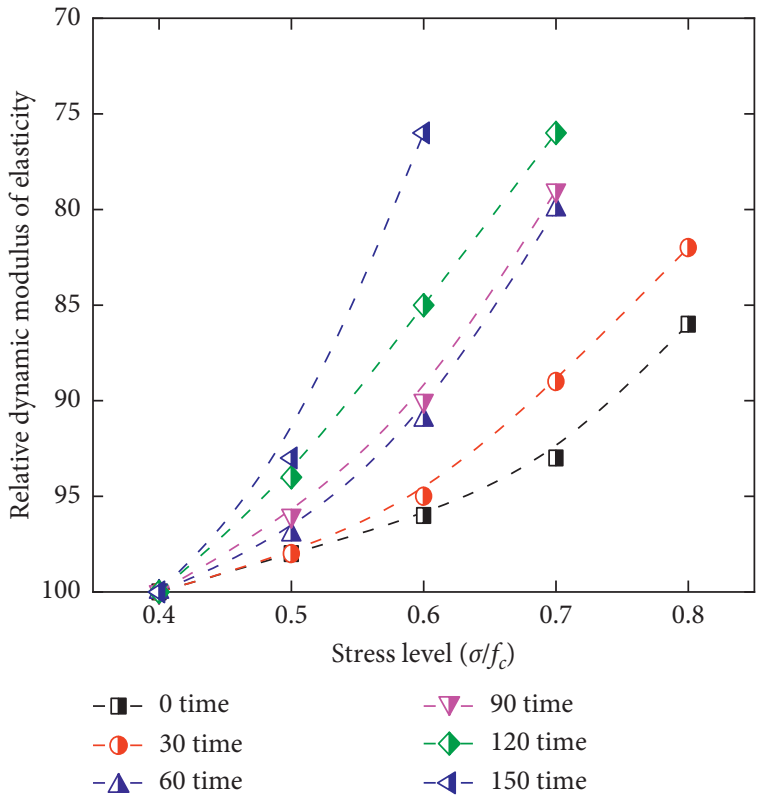

(b)

Figure 8: Variations of $\beta$ (a) with the stress level and the relationship between the stress level and the relative dynamic elastic modulus (b). (a) $\beta$ and stress level. (b) Stress level and relative dynamic elastic modulus.

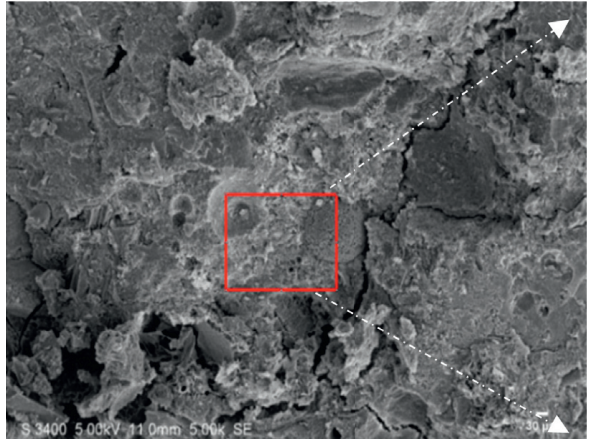

(a)

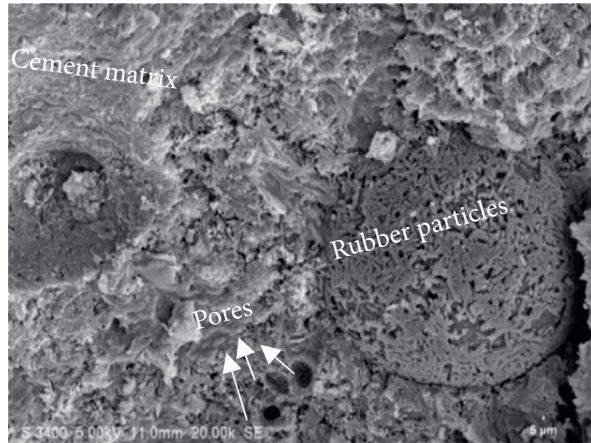

(b)

Figure 9: 0 freeze-thaw cycles. (a) SEM image of CRC. (b) Partially enlarged view of matrix cohesiveness.

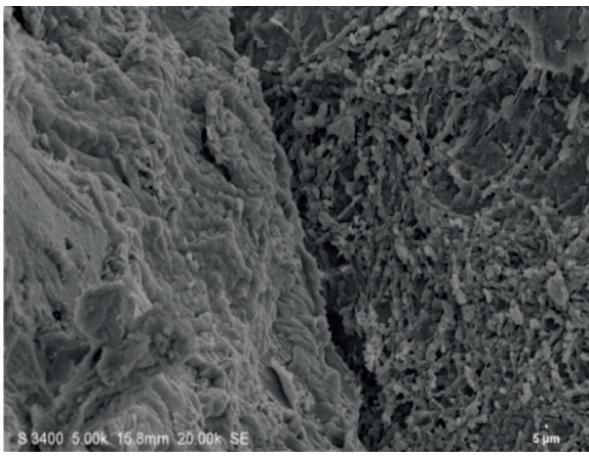

Figure 10: 30 freeze-thaw cycles.

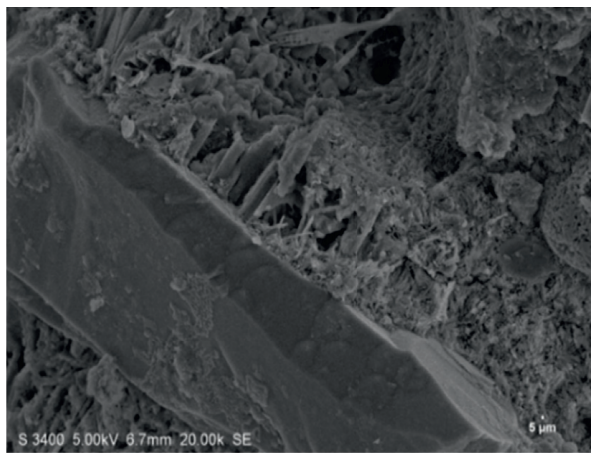

Figure 11: 60 freeze-thaw cycles. the cement paste are relatively tightly bonded, such as a large amount of CSH gel, after ettringite crystals and $\mathrm{Ca}(\mathrm{OH})_{2}$. After 30 cycles of freeze-thaw, it can be seen from Figure 10 that loose began to appear in the concrete matrix and the debonding between the matrix and the rubber particles was observed. After 60 cycles, as shown in Figure 11, more pores 


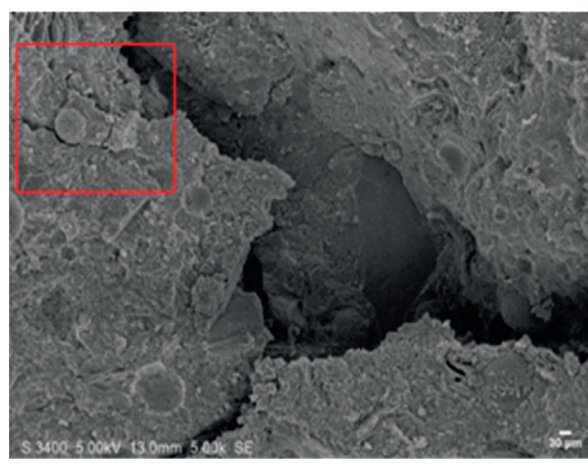

(a)

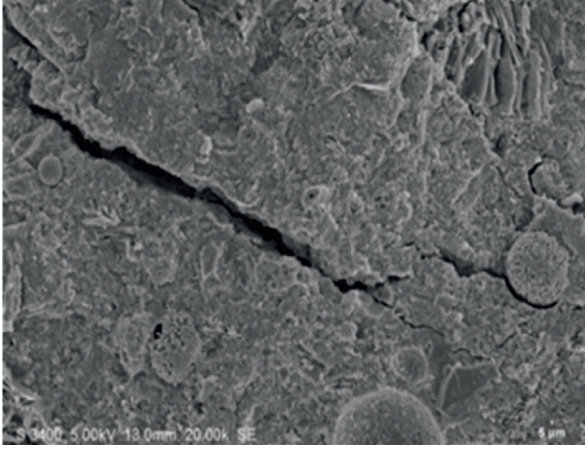

(b)

Figure 12: 90 freeze-thaw cycles. (a) SEM image of CRC. (b) Partially enlarged view of matrix cohesiveness.

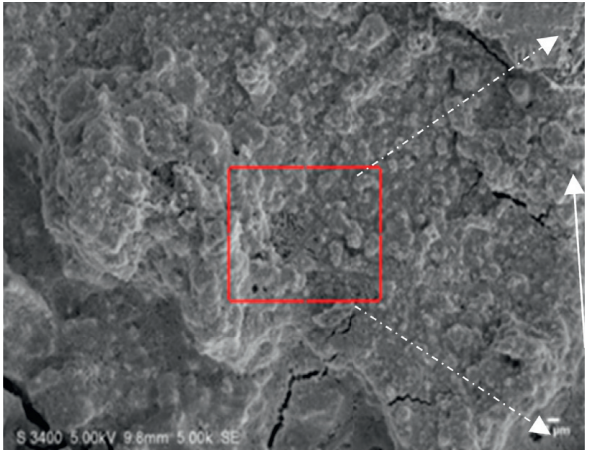

(a)

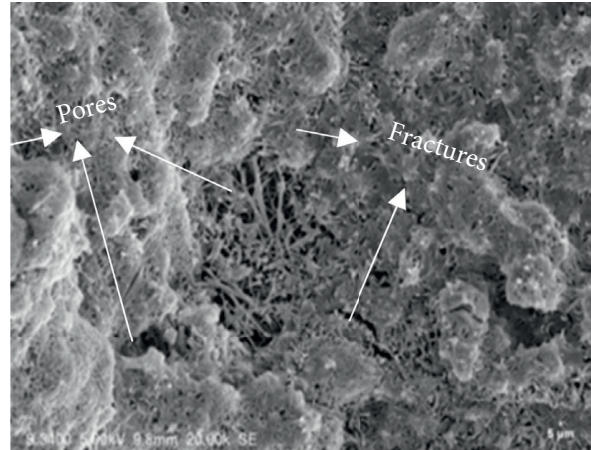

(b)

FIGURE 13: 120 freeze-thaw cycles. (a) SEM image of CRC. (b) Partially enlarged view of matrix cohesiveness.

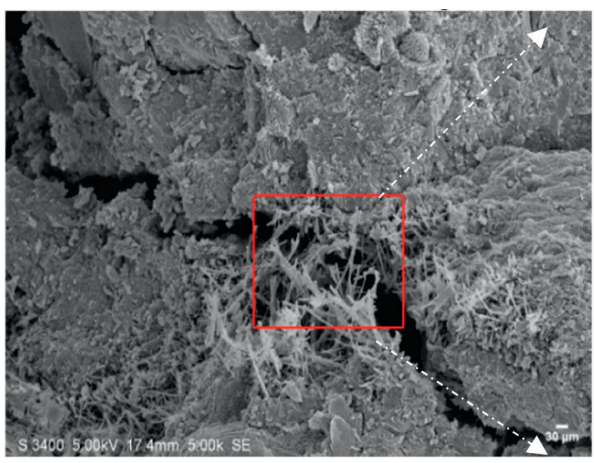

(a)

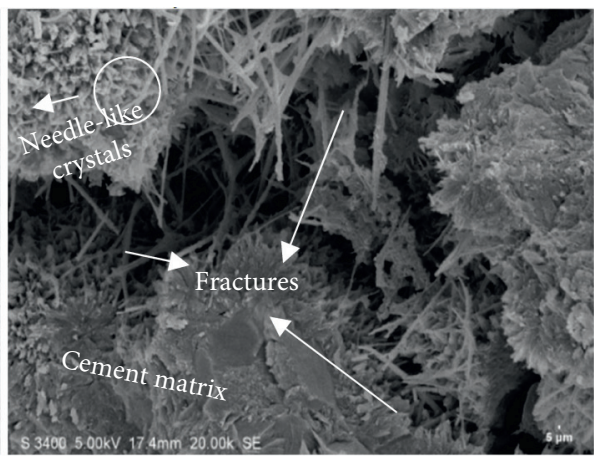

(b)

FIgure 14: 150 freeze-thaw cycles. (a) SEM image of CRC. (b) Partially enlarged view of matrix cohesiveness.

in the needle-like crystals and the interface between the rubber particle and the matrix were found. Compared with the 0 -cycle CRC, the compressive strength decreased by $22.6 \%$, and the relative dynamic elastic modulus decreased by $31.59 \%$.

The CRC matrix is a heterogeneous composite, which is composed of rubber particles, sand, stone, cement hydration mechanism, and matrix-free water. Each constituent has a different thermal expansion coefficient. Under the influence of cyclic freeze-thaw conditions, the incompatible deformation between constituents can result in the initiation, propagation, and coalescence of microcracks. Figure 12(b) shows the morphology of CRC specimens after 90 cycles of freeze-thaw tests; it can be seen that the microcracks developed and coalesced compared to CRC experiencing 0 cycles. Under this condition, its compressive strength and relative dynamic elastic modulus decreased by $28.75 \%$ and $36.87 \%$, respectively.

When the specimens were subjected to more cyclic freeze-thaw, their bonding performance was further degraded or even completely debonded. From the partially enlarged view in Figure 13(b), it can be found that the 
internal pores and small cracks in CRC became obvious after 120 freeze-thaw cycles. The internal pores of the CRC increased, and the strength decreased. As for specimens subjected to 150 freeze-thaw cycles, as shown in Figure 14(b), the increasing porosity and serious cracking were observed in the structure of the CRC specimens.

\section{Creep Damage Model of CRC under Freeze- Thaw Conditions}

As discussed above, it can be concluded that as the number of freeze-thaw cycles increases, small defects randomly develop in the rubber concrete. Furthermore, these defects can eventually penetrate the concrete during the long-term service of the CRC structures. This microscopic damage is unrecoverable and can reduce the effective force area, significantly affecting the macroscopic mechanical properties of the material. In order to analyze the rubber concrete's relationship between the nonlinear mechanical behavior and the mesouniformity in the process of creep damage, it is necessary to use the statistical method of probability to establish the empirical formula of the creep damage of the rubber concrete, which has very important practical significance.

Based on the chain model, the structure is supposed to be composed of many unrelated microunits in Weibull theory, and the destruction of each unit is random; besides, each unit area is quantified by a set of independent variables obeying a certain random distribution, and the failure strength of the entire structure is determined by the weakest unit using the chain effect model. To predict the structure duration, this paper used the two-parameter continuous distribution model based on the Weibull probability theory to fit the empirical formula for creep failure under different stress levels and the different number of freeze-thaw cycles, providing a reference for the application of CRC in related projects.

Assume that $f(t)$ is the probability density function of the time of concrete creep damage failure:

$$
f(t)=\frac{\beta}{\alpha}\left(\frac{t}{\alpha}\right)^{\beta-1} \exp \left(-\left(\frac{t}{\alpha}\right)\right)^{\beta},
$$

where $\alpha$ is the scale function; $\beta$ is the Weibull shape parameter; $t$ is the creep failure time under different strains and different freeze-thaw cycles. After the corresponding CRC undergoes creep damage in a freeze-thaw environment, its life distribution function can be expressed as

$$
P(t)=1-\exp \left(-\left(\frac{t}{\alpha}\right)\right)^{\beta} .
$$

It can be found that when $\beta<1$, the service life of the test piece decreases with the creep damage time; when $\beta=1$, the service life of the test piece tends to be constant; when $\beta>1$, the service life of the test piece increases with the creep damage time.
After shifting term and taking the logarithm, equation (7) can be rephrased as

$$
\ln (\ln (1 / 1-p(t)))=\beta \ln t-\beta \ln \alpha .
$$

By defining $y=\ln (\ln (1 / 1-p(t))), \quad b=-\beta \ln \alpha$, $x=\ln t$, and $a=\beta$, it can be simplified to

$$
y=a x+b
$$

The empirical formula for the failure possibility of CRC specimens can be given by [51]

$$
p=\frac{i-0.3}{m+0.4}
$$

where $i$ is the sequence number of the CRC specimen's creep failure time from small to large; $m$ is the number of specimens in each group, $m=6$. Furthermore, equation (7) can be drawn in Figure 15 based on the test results.

It can be seen that there were big differences when the stress was in the range of $0.5-0.8$, indicating that the creep damage of CRC varies significantly with the train level. Besides, $R^{2}$ is maintained above 0.9 , indicating that $\ln (\ln (1 /$ $1-p(t)))$ and lnt have a high correlation and the empirical formula is highly reliable; the characteristic parameters are shown in Table 4.

Because the CRC creep damage is discrete and the relationship curve between creep damage and failure time is not a single correspondence, the survival rate $p$ needs to be taken into account. Generally, the $S$ - $t$ curve with the median survival rate $p=50 \%$ is used in the prediction models; however, to guarantee the reliability of CRC, the $P$ - $S$ - $t$ curve can be used to express the creep damage life curves with different survival rates; by setting the survival rate to be $95 \%$, $90 \%, 80 \%, 70 \%, 60 \%$, and $50 \%$ as the matrix, the creep failure behavior of RC can be determined by using the double logarithmic creep failure equations (equations (10) and (11)) and the fitted P-S-t curve is shown in Figure 16.

$$
\begin{aligned}
\lg S & =\lg a-b \lg t \\
t_{a} & =\frac{\ln (\ln (1 / 1-p(t)))+\beta \ln \alpha}{\beta},
\end{aligned}
$$

where $S$ is the maximum strain level; $a$ and $b$ are the intercept and slope of the $P$-S- $t$ curve, respectively; $t$ is the time of creep damage. It can be found that the larger $a$, the higher the CRC resistance to creep damage, and the larger $b$, the less sensitivity of the CRC creep damage to changes in strain.

It can be seen from Figure 16 that the fitted curve was approximately straight, and the correlation coefficient $R^{2}$ was greater than 0.95 , indicating that the double logarithmic $P$-S- $t$ equation can better describe the relationship between CRC creep damage and strain level. If the survival rate is determined in the actual engineering, the corresponding $P$ - $S$ - $t$ creep damage empirical formula can be calculated by equation (11), as shown in Table 5. 


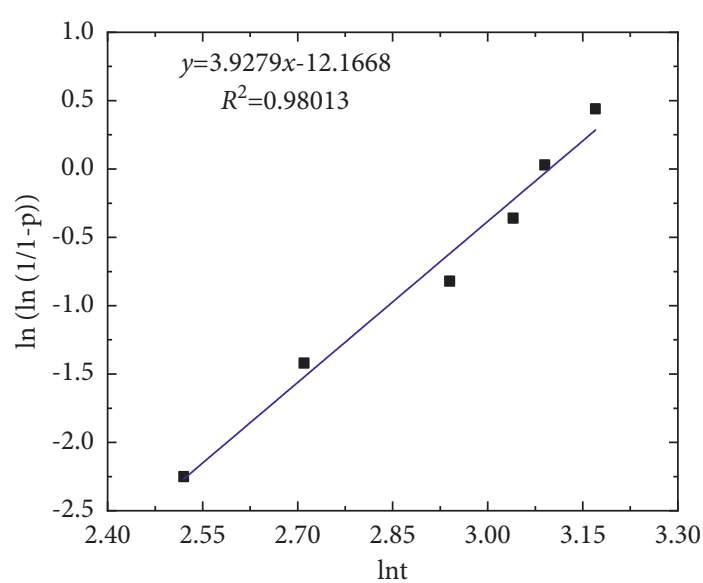

(a)

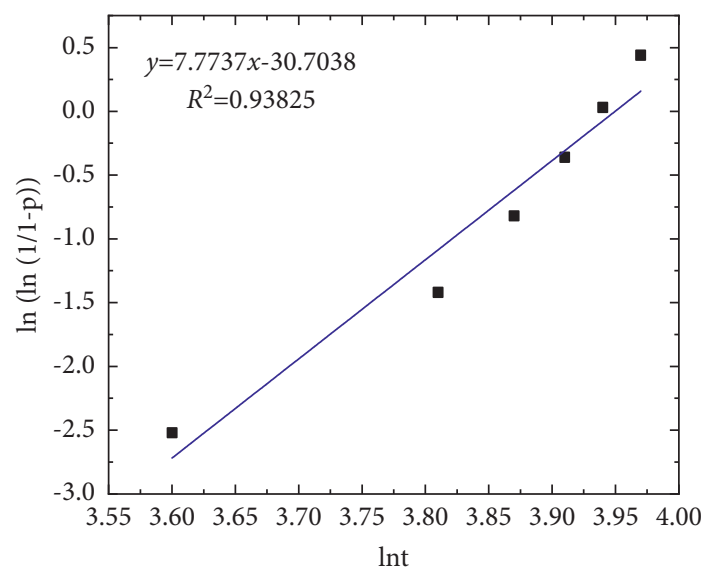

(c)

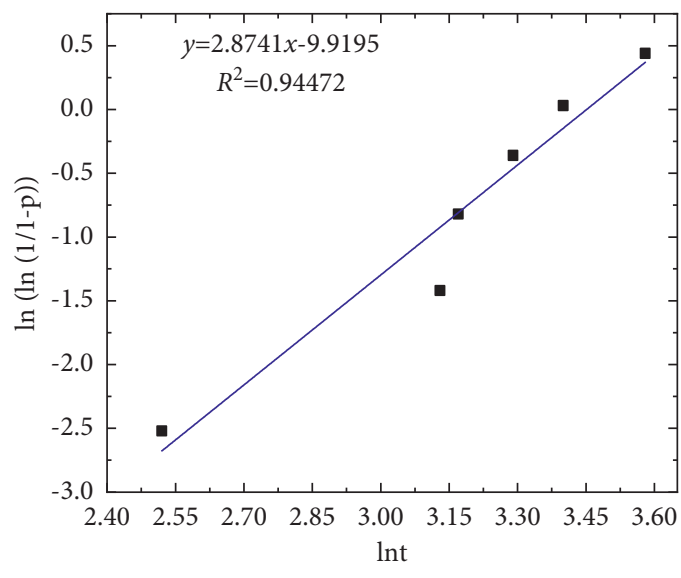

(b)

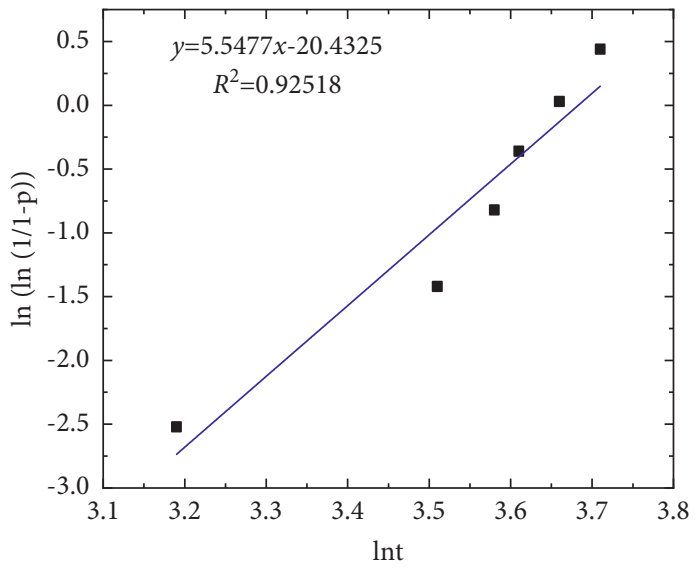

(d)

Figure 15: $\ln (\ln (1 / 1-p(t)))$ curves under different stress levels: (a) $\sigma-0.5$, (b) $\sigma-0.6$, (c) $\sigma-0.7$, and (d) $\sigma-0.8$.

TABLE 4: Characteristic parameters of Weibull distribution.

\begin{tabular}{lcccc}
\hline Strain level & $\beta$ & $B$ & $\alpha$ & $R^{2}$ \\
\hline 0.5 & 1.8949 & -6.1614 & 372.41 & 0.9473 \\
0.6 & 2.9257 & -10.7248 & 273.14 & 0.9283 \\
0.7 & 4.1157 & -16.2196 & 228.15 & 0.9416 \\
0.8 & 4.6147 & -18.6738 & 217.02 & 0.9760 \\
\hline
\end{tabular}




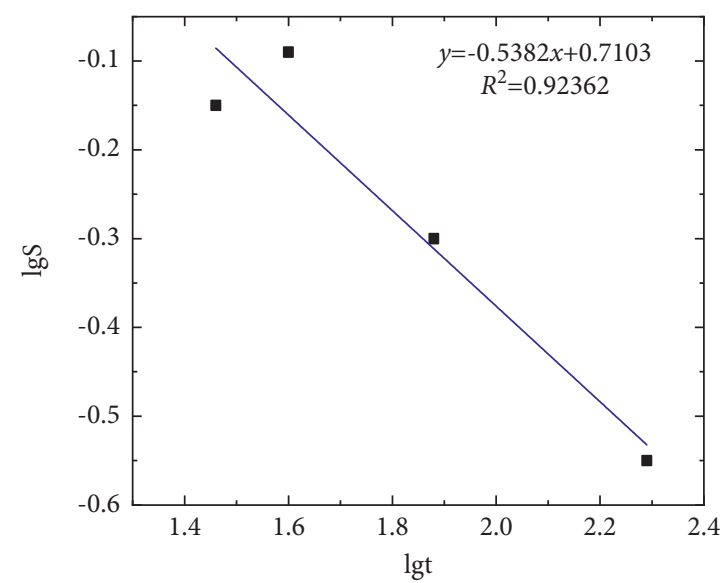

(a)

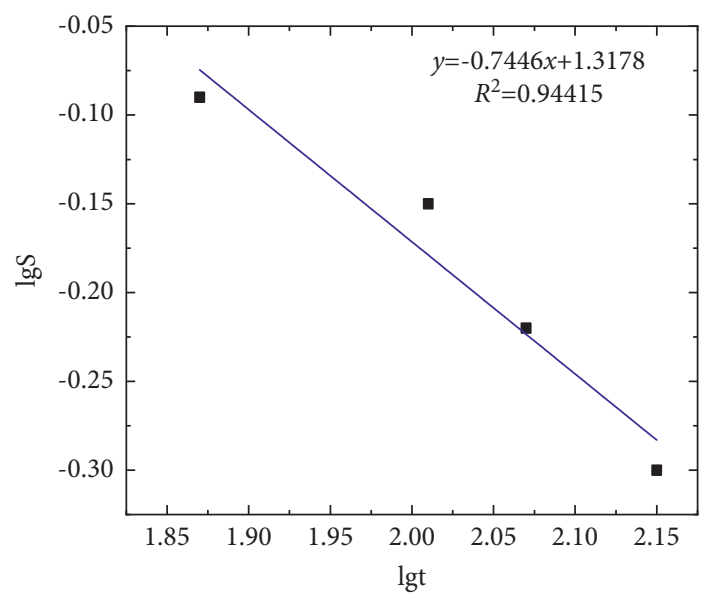

(c)

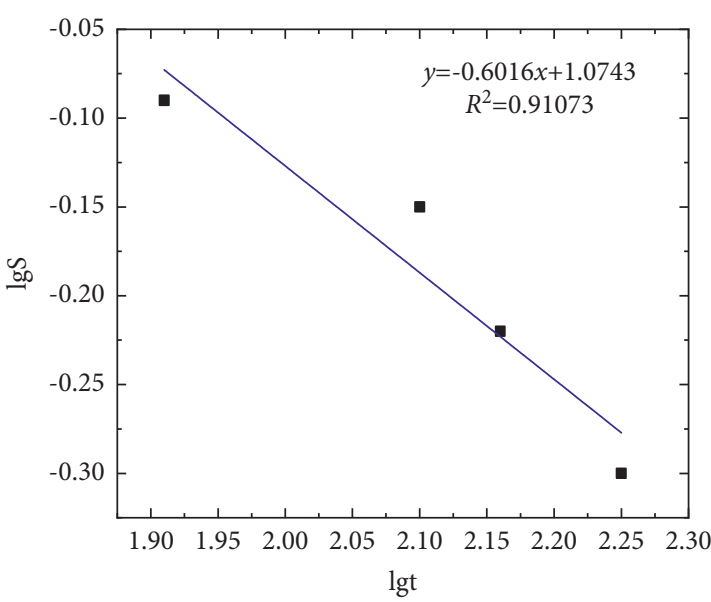

(e)

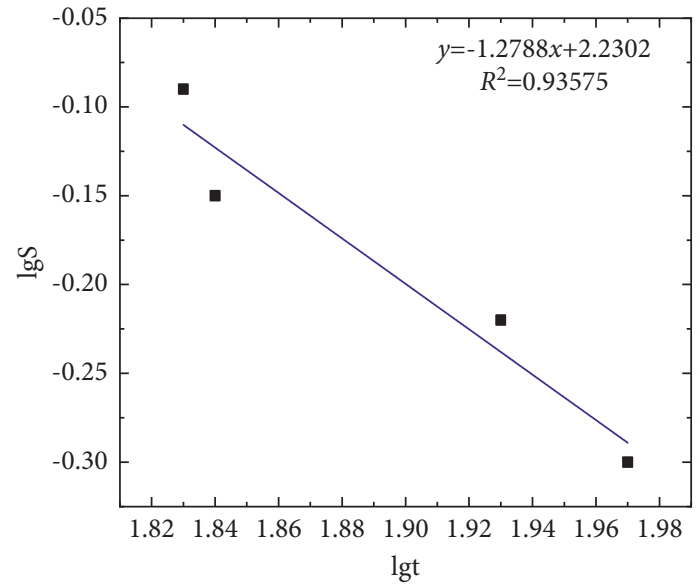

(b)

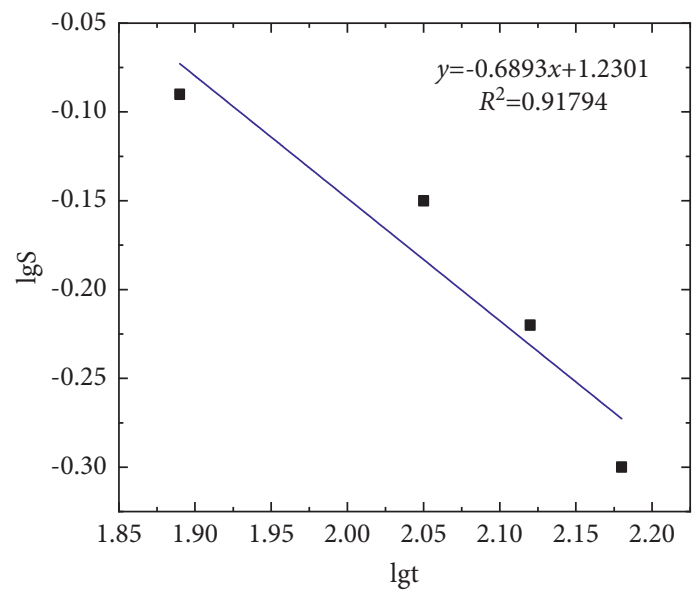

(d)

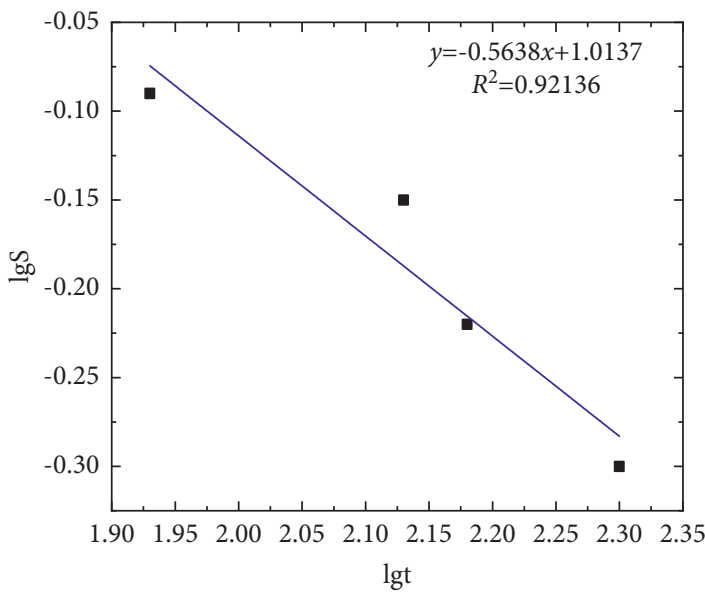

(f)

Figure 16: P-S-N curves under different survival rates: (a) p-95\%, (b) p-90\%, (c) p-80\%, (d) p-70\%, (e) p-60\%, and (f) p-50\%.

TABLE 5: CRC creep damage and failure prediction equation parameters.

\begin{tabular}{lccr}
\hline Survival rate & $b$ & $\lg a$ & $R^{2}$ \\
\hline 0.05 & -0.7182 & 1.7938 & 0.95830 \\
0.1 & -0.8047 & 1.9884 & 0.95778 \\
0.2 & -0.8996 & 2.1824 & 0.96670 \\
0.3 & -1.0595 & 2.5353 & 0.95603 \\
0.4 & -1.2630 & 2.9798 & 0.96555 \\
0.5 & -1.5094 & 3.5157 & 0.95354 \\
\hline
\end{tabular}




\section{Conclusions}

(1) The amount of spalling of Crumb Rubber Concrete (CRC) specimens gradually increased with the number of freeze-thaw cycles, especially after 60 freeze-thaw cycles. Meanwhile, the edges and corners of the specimens were no longer distinct, and the surface significantly became rough after 150 freezethaw cycles. Ultimately, the maximum mass loss rate was around $11.2 \%$.

(2) The compressive strength decreased with the freezethaw cycle. After 30-150 freeze-thaw cycles, the compressive strength declined by $6.51 \%-47 \%$.

(3) Under freeze-thaw conditions, the microcracks of the CRC matrix gradually developed and penetrated, and the interfacial bond between the rubber particles and the concrete was gradually weakened or even completely deboned. The internal pores and cracks in the bonding surface of the CRC are visible, which are the main reasons for the decrease of the mechanical and creep properties.

(4) According to experimental data of the CRC creep damage, an empirical creep damage model for CRC under cyclic freeze-thaw conditions was established by using the two-parameter Weibull probability distribution function. The results show that the correlation coefficient between the test data and the empirical model is above 0.9 , which shows a high degree of fit. It can provide a reference for the study of CRC creep damage under similar engineering conditions. However, this semiempirical model is founded on the specific type of CRC, and the effects of mixture proportions (i.e., the water/cement ratio, the content of aggregates and rubbers, and the cement type) and curing conditions are not taken into consideration, which needs further study.

\section{Data Availability}

All data, models, and codes generated or used during the study appear in the submitted article.

\section{Conflicts of Interest}

The authors declare there are no conflicts of interest.

\section{Acknowledgments}

The authors acknowledge the financial support from the Institute of Rock and Soil Mechanics, Young Talent Top Project of Hebei Province (BJ2020055), Open Research Fund of State Key Laboratory of Geomechanics and Geotechnical Engineering, Institute of Rock and Soil Mechanics, Chinese Academy of Sciences (Grant no. Z018014), and China Postdoctoral Science Foundation (no. 2019M663553).

\section{References}

[1] B. S. Thomas and R. C. Gupta, "A comprehensive review on the applications of waste tire rubber in cement concrete," Renewable and Sustainable Energy Reviews, vol. 54, pp. 1323-1333, 2016.

[2] A. Benazzouk, O. Douzane, T. Langlet, K. Mezreb, J. M. Roucoult, and M. Quéneudec, "Physico-mechanical properties and water absorption of cement composite containing shredded rubber wastes," Cement and Concrete Composites, vol. 29, pp. 732-740, 2007.

[3] B. S. Thomas, R. C. Gupta, P. Kalla, and L. Cseteneyi, "Strength, abrasion and permeation characteristics of cement concrete containing discarded rubber fine aggregates," Construction and Building Materials, vol. 59, pp. 204-212, 2014.

[4] Y. Shen, "Research status and development prospects of road rubber concrete," Guangdong Civil Engineering and Construction, vol. 26, pp. 32-36, 2019, in Chinese.

[5] B. Adhikari, "Reclamation and recycling of waste rubber," Progress in Polymer Science, vol. 25, pp. 909-948, 2000.

[6] B. S. Mohammed, A. B. Awang, S. S. Wong, and C. P. Nhavene, "Properties of nano silica modified rubbercrete," Journal of Cleaner Production, vol. 119, pp. 66-75, 2016.

[7] H. A. Toutanji, "The use of rubber tire particles in concrete to replace mineral aggregates," Cement and Concrete Composites, vol. 18, pp. 135-139, 1996.

[8] O. Youssf, M. A. ElGawady, J. E. Mills, and X. Ma, "An experimental investigation of crumb rubber concrete confined by fibre reinforced polymer tubes," Construction and Building Materials, vol. 53, pp. 522-532, 2014.

[9] N. N. Eldin and A. B. Senouci, "Rubber-Tire particles as concrete aggregate," Journal of Materials in Civil Engineering, vol. 5, pp. 478-496, 1993.

[10] K. Bisht and P. V. Ramana, "Evaluation of mechanical and durability properties of crumb rubber concrete," Construction and Building Materials, vol. 155, pp. 811-817, 2017.

[11] T. Gupta, S. Chaudhary, and R. K. Sharma, "Assessment of mechanical and durability properties of concrete containing waste rubber tire as fine aggregate," Construction and Building Materials, vol. 73, pp. 562-574, 2014.

[12] C. A. Issa and G. Salem, "Utilization of recycled crumb rubber as fine aggregates in concrete mix design," Construction and Building Materials, vol. 42, pp. 48-52, 2013.

[13] B. Z. Savas, S. Ahmad, and D. Fedroff, "Freeze-thaw durability of concrete with ground waste tire rubber," Transportation Research Record, vol. 1574, pp. 80-88, 1997.

[14] P. Sukontasukkul and C. Chaikaew, "Properties of concrete pedestrian block mixed with crumb rubber," Construction and Building Materials, vol. 20, pp. 450-457, 2006.

[15] B. Zhang, F. Yuan, J. Xie, D. Lai, Y. Ting, and D. Huang, "Rubberized geopolymer concrete: dependence of mechanical properties and freeze-thaw resistance on replacement ratio of crumb rubber," Construction and Building Materials, vol. 310, pp. 0950-0618, 2021.

[16] T. Gupta, R. K. Sharma, and S. Chaudhary, "Impact resistance of concrete containing waste rubber fiber and silica fume," International Journal of Impact Engineering, vol. 83, pp. 76-87, 2015.

[17] J. Lv, T. Zhou, Q. Du, and H. Wu, "Effects of rubber particles on mechanical properties of lightweight aggregate concrete," 
Construction and Building Materials, vol. 91, pp. 145-149, 2015.

[18] K. C. Panda and P. K. Bal, "Properties of self compacting concrete using recycled coarse aggregate," Procedia Engineering, vol. 51, pp. 159-164, 2013.

[19] A. Yilmaz and N. Degirmenci, "Possibility of using waste tire rubber and fly ash with Portland cement as construction materials," Waste Management, vol. 29, pp. 1541-1546, 2009.

[20] L. Wang, X. Zeng, H. Yang, and X. Lv, "Investigation and application of fractal theory in cement-based materials: a review," Fractal and Fractinal, vol. 5, no. 4, p. 247, 2021.

[21] İB. Topçu and A. Demir, "Durability of rubberized mortar and concrete," Journal of Materials in Civil Engineering, vol. 19, pp. 173-178, 2007.

[22] J. Xu, Z. Fu, Q. Han, G. Lacidogna, and A. Carpinteri, "Microcracking monitoring and fracture evaluation for crumb rubber concrete based on acoustic emission techniques," Structural Health Monitoring, vol. 17, pp. 946-958, 2018.

[23] W. H. Yung, L. C. Yung, and L. H. Hua, "A study of the durability properties of waste tire rubber applied to selfcompacting concrete," Construction and Building Materials, vol. 41, pp. 665-672, 2013.

[24] L. Wang, R. Luo, and W. Zhang, "Effects of fineness and content of phosphorus slag on cement hydration, permeability, pore structure and fractal dimension of concrete," Fractals, vol. 29, no. 2, Article ID 2140004, 2021.

[25] L. Wang, G. Li, and F. Guo, "Influence of reactivity and dosage of $\mathrm{MgO}$ expansive agent on shrinkage and crack resistance of face slab concrete," Cement and Concrete Composites, vol. 2021, Article ID 104333, 2021.

[26] J. Huang, W. Li, and D. Huang, "Fractal analysis on pore structure and hydration of magnesium oxysulfate cements by first principle, thermodynamic and microstructure-based methods," Fractal. Fract, vol. 5, no. 4, p. 164, 2021.

[27] G. Xue and Z. Pei, "Experimental study on axial compressive properties of rubber concrete at low temperature," Journal of Materials in Civil Engineering, vol. 30, Article ID 04017301, 2018.

[28] M. Hora and P. Reiterman, Assessment of the air-entraining effect of rubber powder and its influence on the frost resistance of concrete 7, 2016.

[29] L. He, Y. Ma, Q. Liu, and Y. Mu, "Surface modification of crumb rubber and its influence on the mechanical properties of rubber-cement concrete," Construction and Building Materials, vol. 120, pp. 403-407, 2016.

[30] N. Segre and I. Joekes, "Use of tire rubber particles as addition to cement paste," Cement and Concrete Research, vol. 30, pp. 1421-1425, 2000

[31] R. Si, S. Guo, and Q. Dai, "Durability performance of rubberized mortar and concrete with $\mathrm{NaOH}$-Solution treated rubber particles," Construction and Building Materials, vol. 153, pp. 496-505, 2017.

[32] R. K. Dhir, M. J. McCarthy, and M. D. Newlands, Use of Crumb Rubber to Achieve Freeze Thaw Resisting concrete, Thomas Telford Publishing, London, UK, 2002.

[33] M. Gesoğlu, E. Güneyisi, G. Khoshnaw, and S. İpek, “Abrasion and freezing-thawing resistance of pervious concretes containing waste rubbers," Construction and Building Materials, vol. 73, pp. 19-24, 2014.
[34] A. E. Richardson, K. A. Coventry, and G. Ward, "Freeze/thaw protection of concrete with optimum rubber crumb content," Journal of Cleaner Production, vol. 23, pp. 96-103, 2012.

[35] F. Hernández-Olivares and G. Barluenga, "Fire performance of recycled rubber-filled high-strength concrete," Cement and Concrete Research, vol. 34, pp. 109-117, 2004 b.

[36] R. Siddique and T. R. Naik, "Properties of concrete containing scrap-tire rubber - an overview," Waste Management, vol. 24, pp. 563-569, 2004.

[37] D. V. Bompa and A. Y. Elghazouli, "Creep properties of recycled tyre rubber concrete," Construction and Building Materials, vol. 209, pp. 126-134, 2019.

[38] O. Youssf, J. E. Mills, T. Benn et al., "Development of crumb rubber concrete for practical application in the residential construction sector - design and processing," Construction and Building Materials, vol. 260, Article ID 119813, 2020.

[39] M. Adamu, "Effect of crumb rubber and nano silica on the creep and drying shrinkage of roller compacted concrete pavement," Geomaterials, vol. 15, no. 47, 2018.

[40] W. V. Srubar, "Stochastic service-life modeling of chlorideinduced corrosion in recycled-aggregate concrete," Cement and Concrete Composites, vol. 55, pp. 103-111, 2015.

[41] H.-S. Choi, W.-S. Seo, and D.-K. Choi, "Prediction of reliability on thermoelectric module through accelerated life test and Physics-of-failure," Electron Mater Lett, vol. 7, pp. 271-275, 2011.

[42] F. Chen and P. Qiao, "Probabilistic damage modeling and service-life prediction of concrete under freeze-thaw action," Materials and Structures, vol. 48, pp. 2697-2711, 2015.

[43] N.-P. Pham, A. Toumi, and A. Turatsinze, "Rubber aggregatecement matrix bond enhancement: microstructural analysis, effect on transfer properties and on mechanical behaviours of the composite," Cement and Concrete Composites, vol. 94, pp. 1-12, 2018.

[44] Y. Gao, "Study on the bending fatigue performance of nanosilica self-compacting road concrete," Journal of Shenyang Jianzhu University (Natural Science Edition), vol. 36, no. 4, pp. 670-679, 2020.

[45] C. Lu, "Reliability life analysis of reinforced concrete in salt corrosion environment based on 3-parameter Weibull distribution," Journal of Engineering Science, vol. 43, no. 4, pp. 512-520, 2021, in Chinese.

[46] GB/T50081-2019, Chinese Standard for Test Methods of concrete Physical and Mechanical Properties, Ministry of Housing and Urban-Rural Development of the People's Republic of China, Beijing, China, 2019.

[47] Z. Yan, Y. Zhang, J. J. Woody, Q. Chen, and H.-H. Zhu, “An equivalent elastoplastic damage model based on micromechanics for hybrid fiber-reinforced composites under uniaxial tension," International Journal of Damage Mechanics, vol. 28, pp. 79-117, 2019.

[48] Y. Zhang, J. W. Ju, H. Zhu, and Z. Yan, "A novel multi-scale model for predicting the thermal damage of hybrid fiberreinforced concrete," International Journal of Damage Mechanics, vol. 29, pp. 19-44, 2020b.

[49] Y. Zhang, J. W. Ju, Q. Chen, Z. Yan, H. Zhu, and Z. Jiang, "Characterizing and analyzing the residual interfacial behavior of steel fibers embedded into cement-based matrices 
after exposure to high temperatures," Composites Part B: Engineering, vol. 191, Article ID 107933, 2020a.

[50] Y. Zhang, Q. Zhou, J. W. Ju, and M. Bauchy, "New insights into the mechanism governing the elasticity of calcium silicate hydrate gels exposed to high temperature: a molecular dynamics study," Cement and Concrete Research, vol. 141, Article ID 106333, $2021 \mathrm{~b}$.

[51] Y. Zhang, J. J. Woody, F. Xu, Z. Yan, and H. Zhu, "A novel micromechanical model of residual fracture energy of hooked-end steel fiber reinforced concrete exposed to high temperature," Construction and Building Materials, vol. 278, Article ID 122211, 2021. 